\title{
Using Functional Models to Understand the Four-Electron Reduction of Dioxygen by Cytochrome c Oxidase Under Steady State Conditions
}

\author{
Department of Chemistry, Stanford University \\ James P. Collman* and Richard A. Decréau \\ Received June 25, 2009; E-mail: jpc@stanford.edu
}

\begin{abstract}
A new functional biomimetic model of cytochrome c oxidase is reported. It is synthesized in 32 steps. Single turnover reaction with oxygen leads to the same intermediates as the ones reported in the enzyme: $\mathrm{Fe}(\mathrm{III}) \mathrm{O}_{2}{ }^{-} / \mathrm{Cu}(\mathrm{I}) / \mathrm{PhOH}$ (oxygen complex), and $\mathrm{Fe}(\mathrm{IV})=\mathrm{O} / \mathrm{Cu}(\mathrm{II}) / \mathrm{PhO}^{*}(\mathrm{PM})$. A sister model derivatized with an alkyne was immobilized on azide-functionnalized self-assembled monolayer (SAM) coated gold electrodes by $\mathrm{Cu}(\mathrm{I})$-catalyzed click chemistry. The rate of electron transfer from the electrode to the model was controlled by the length of the linker in the SAM. Steadystate turnover was achieved at biologically relevant electron transfer, where $\mathrm{CuB}$ and $\mathrm{Tyr} 244$ mimics rapidly deliver their electrons, hence minimizing the release of partially reduced oxygen species (PROS).
\end{abstract}

\section{Introduction}

Oxidative phosphorylation generates most of the energy in our bodies. This respiratory process occurs in the mitochondria, where electrons derived from food are delivered, one at a time by a coordinatively-saturated hemeprotein, cyctochrome $\mathrm{c}$ (Cyt. c) to the terminal respiratory enzyme cytochrome c oxidase $(\mathrm{CcO}){ }^{1,2}$ The reaction of dioxygen at the active site of $\mathrm{CcO}$ with four protons and four electrons produces water. Exergonic electron/proton transfers to dioxygen are coupled to endergonic transfers of additional protons across the mitochondrial membrane. As a result four additional protons are driven to the cytosolic (outer) side of the membrane, and the resulting proton gradient is relaxed as protons flow back through another enzyme, ATPase. ${ }^{1-3}$ This allows the biosynthesis of adenosine triphosphate (ATP) which is a crucial energy storage source required for many life-supporting processes in the body. Equation 1 summarizes the overall four-electron reduction of dioxygen catalyzed by $\mathrm{CcO}$ and the pumping of four protons.

$$
\mathrm{O}_{2}+8 \mathrm{H}^{+} \text {(inner) } \rightarrow 2 \mathrm{H}_{2} \mathrm{O}+4 \mathrm{H}^{+} \text {(outer) }
$$

Corresponding Author: James P. Collman

Address: Department of Chemistry, Stanford University, 333 Campus Drive, USA

Tel: 650-725-0283 Fax: 650-725-0259

Keywords:oxygen reduction, oxygen complex, electron transfer, steady-state, self-assembled monolayer, electrode, functional model, tyrosine.
Dysfunctions in the oxygen/energy metabolism are associated with the release of partially-reduced oxygen species (PROS) during the reduction of $\mathrm{O}_{2}$ by $\mathrm{CcO}$. These include superoxide (HOO), peroxide $(\mathrm{HOOH})$, and hydroxyl radical (HO). ${ }^{1}$ Such species are highly toxic, causing cell damage. This so-called oxidative stress is involved in the pathology of several diseases, such as Alzheimer's disease, stroke, diseases of the nervous system, and cardiovascular disorders. ${ }^{4}$ Hence it is crucial that $\mathrm{CcO}$ reduces $\mathrm{O}_{2}$ with a high degree of selectivity, without releasing PROS. $\mathrm{CcO}$ is bound to the inner mitochondrial membrane, and a few crystal structures of its active site (from beef heart and P. denitrificans) have been reported. ${ }^{5-7}$ Bovine $\mathrm{CcO}$ possesses four redox-active metal centers: a bimetallic reaction center consisting of a myoglobin-like $(\mathrm{Mb})$ group (heme a3) and a tricoordinated copper atom on the distal side $\left(\mathrm{Cu}_{\mathrm{B}}\right)$, a six-coordinate lowspin heme a, and a binuclear copper complex $\left(\mathrm{Cu}_{\mathrm{A}}\right) . \mathrm{CcO}$ also possesses organic redox-active residues in the vicinity of its active site, such as a tyrosine (Tyr244) which in most active heme/Cu terminal oxidases underwent post-translational modification resulting in Tyr244 being covalently cross-linked to the His240 residue. ${ }^{8,9}$ Resonance Raman and EPR analyses have characterized some of the intermediate stages that occur during single turnover experiments. Hence there is a consensus concerning some of the intermediates and the sequence of reactions involving the five redox-centers that occur during the reduction of oxygen by $\mathrm{CcO}$. Reduction of oxygen can occur in the fully reduced enzyme (6 available electrons) or in 
a partially-reduced enzyme (mixed valence) where heme a and $\mathrm{CuA}$ are oxidized and the active site is reduced (4 available electrons). The rate at which electrons are transferred one-at-atime by cyt. $\mathrm{c}$ to $\mathrm{CcO}$ is much slower than the rates of internal electron transfer between the various redox sites in $\mathrm{CcO}$ (Fig. 1). Hence, during steady-state turnover (when the enzyme continuously reduces dioxygen), $\mathrm{CcO}$ is always starved for electrons which suggests that the mixed valence state must be involved. ${ }^{2}$ As a result, a supply of electrons from a nearby organic redox-active center becomes important for partially reduced $\mathrm{CcO}$ to reduce dioxygen without leaking PROS. Several studies suggested Tyr244 to be the likely source of the fourth electron ${ }^{9-11}$ and a proton in the mixed valence enzyme. ${ }^{12}$ Mimicking the active site of cytochrome c oxidase may be important for two reasons: 1) a model is well defined, hence it could help understand the mechanism of oxygen reduction by $\mathrm{CcO}$, and hence is relevant to health-related matters; 2) $\mathrm{CcO}$ is at the heart of the mammalian energy machinery and hence should be a source of inspiration for the development of bioinspired catalysts in the context of energy-related matters.

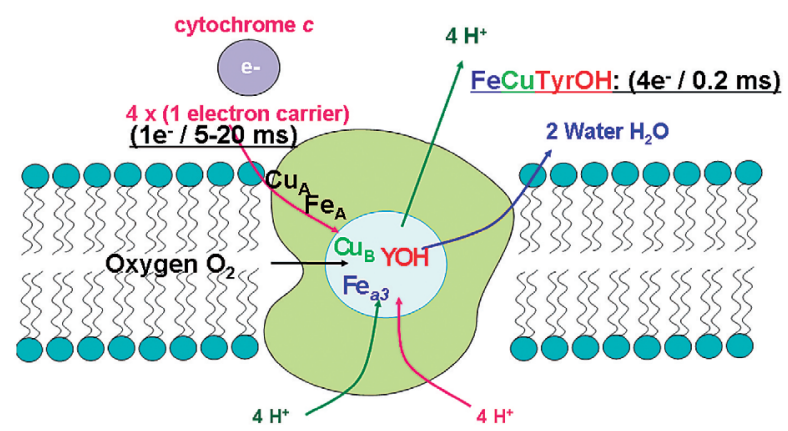

Fig. 1 Membrane-bound cytochrome c oxidase and electron carrier cytochrome c.

\section{Synthesis of the $\mathrm{CcO}$ model}

Based on crystal structures of the enzyme, ${ }^{5-7,13}$ models 1 and 2 were synthesized with an $\mathrm{FeCu}$ distance within $5 \AA$. The electron count shows that $2 \mathrm{e}$ - come from Fe, 1e- from $\mathrm{Cu}$, and 1e- from Tyr244 (Fig. 2). The model was synthesized in 32 steps, starting from an $\alpha_{3} \beta$-porphyrin atropisomer synthon, and three different imidazoles synthons: a crosslinked imidazole-phenol mimicking His240-Tyr244, an imidazole tail on the proximal face mimicking His376, and two simpler imidazoles mimicking His290 and His291 (Fig. 2). ${ }^{14-17}$ Earlier models had a $\mathrm{CF}_{3}$ group that had dual purposes: a) it was used as a fluorine marker in ${ }^{19} \mathrm{~F}$-NMR to estimate the number of $\mathrm{Cu}$ inserted in the distal pocket, by comparing the integration of the fluorinated counter-ion, b) it also played a useful role during the chromatographic separation of crucial

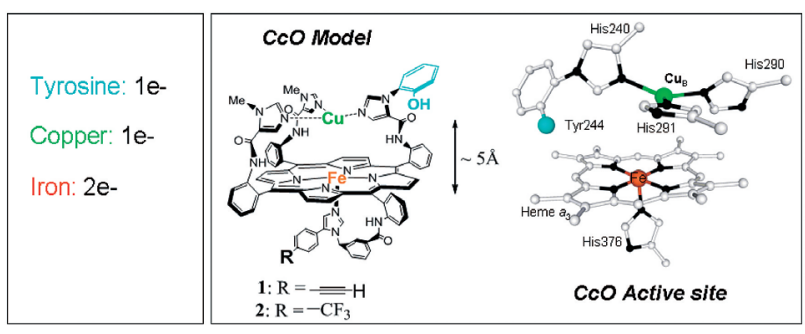

Fig. 2 Heme iron, $\mathrm{Cu}$ and Phenol: the electron count in $\mathrm{CcO}$ models 1-2 and in the $\mathrm{CcO}$ active site.

regioisomeric intermediates. ${ }^{15}$ The modular synthesis of the synthons allowed the introduction of the alkyne function in place of the $\mathrm{CF}_{3}$ group. Bromination of acetophenone followed by condensation with formamide led to imidazole ring cyclisation. Upon Horvath-type protection by Michael addition with acrylonitrile, regioselective quaternisation of the imidazole with a bromoester and removal of the cyanoethyl protective group, the resulting ester-imidazole synthon was saponified and converted to acyl chloride $\mathbf{1 0}$ (Fig. 3). Note that the alkyne function could be introduced at various stages of the synthesis, either at the Michael acceptor 4 or ester 7 stages, or even when the imidazole was already attached to the porphyrin. ${ }^{14}$ Imidazole synthon $\mathbf{1 8}$ bearing the tyrosine mimic was synthesized by methylation and amidation of 2-aminophenol. ${ }^{14,18}$ Upon deprotonation and alkylation of the amide, the resulting $N$-aryl glycine ester 12 was formylated and annulated by cycloaddition with HSCN. The resulting mercaptoimidazole was desulfurized in a mixture containing tungstic acid, and the resulting ester imidazole was later saponified and converted into its acyl chloride 18. The simple imidazole picket $\mathbf{2 3}$ ' was prepared by condensation of triethylorthoformate with diaminomaleonitrile leading to a dicyanoimidazole which upon methylation undergoes regioselective acyl-catalyzed decarboxylation. ${ }^{19}$ The major 5-carboxylato regioisomer is converted to an acyl chloride.

The porphyrin synthon 26 (Fig. 4) was synthesized by

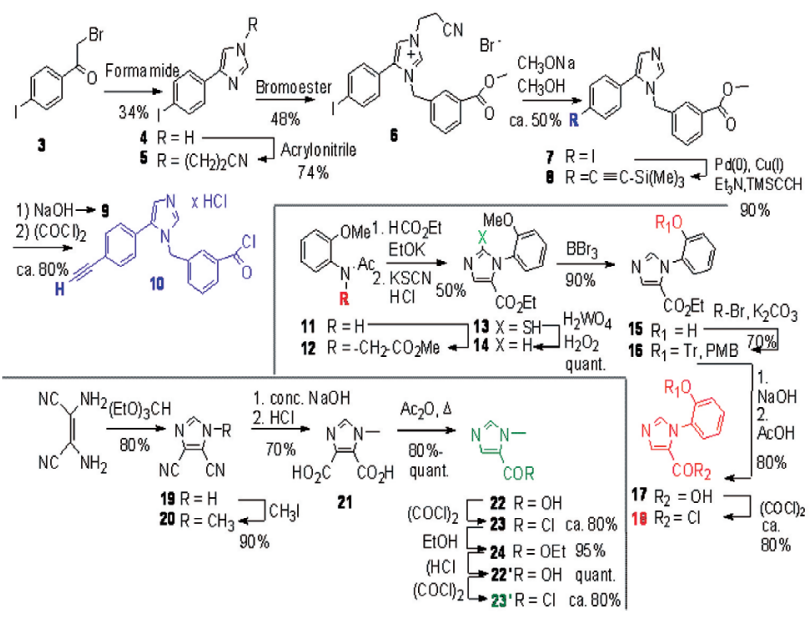

Fig. 3 Syntheses of imidazole synthons (pickets and tail). ${ }^{14,15, ~ 17, ~ 19, ~} 20$ 
undergoing porphyrin face selection upon reaction of a mixture of atropisomer of tetra-aminophenyl porphyrin (TAPP) with trityl bromide followed by atropisomer enrichment on activated alumina. ${ }^{16}$ Upon protection of the distal amines into electrodeficient amides and cleavage of the proximal protective group, the resulting porphyrin $\mathbf{2 8}$ is acylated with the imidazole tail synthon $\mathbf{1 0}$ (Fig. 4). The distal amines were deprotected, and successively acylated with the "simple" imidazole 23', and the Tyr244-mimiccontaining imidazole pickets 18 (Fig. 5). These steps required delicate chromatographic separations on a chromatotron, a rotative chromatography method. Metallation of the porphyrin with iron in the presence of an excess of iron reagent was accompanied with insertion of iron in the distal pocket which was removed by treatment with a strong chelator, EDTA, resulting in a free distal pocket which was subsequently metallated with copper leading to $\mathbf{1 - 2}{ }^{20}$

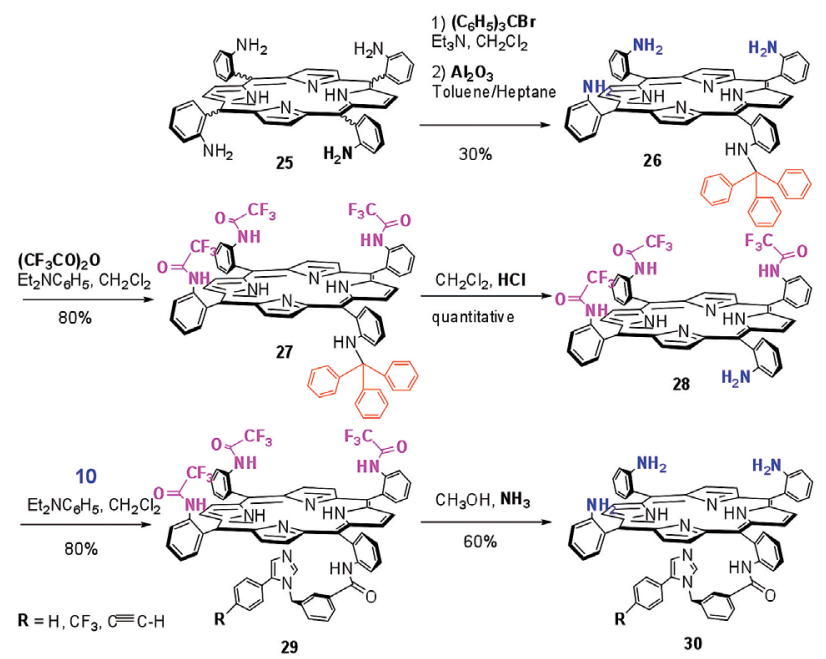

Fig. 4 Synthesis of an imidazole-tailed porphyrin with a distal trisaminophenyl plateform. ${ }^{14,15,17,20}$
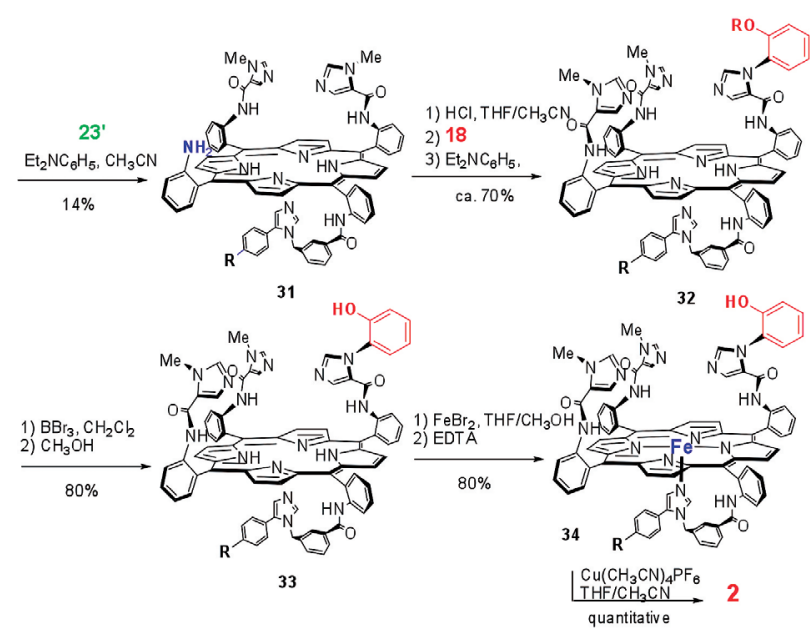

Fig. 5 Appending of the imidazole pickets on a tailed porphyrin, and metallations with iron and copper. ${ }^{14,15,17,20}$

\section{Single turnover studies}

The oxygenation of the $\mathrm{Fe}(\mathrm{II}) \mathrm{Cu}(\mathrm{I})$ model at low temperature leads to an oxygen complex (Fig. 6) having the resonance Raman signature of an $\mathrm{Fe}(\mathrm{III}) \mathrm{O}_{2}{ }^{-}{ }^{-} / \mathrm{Cu}(\mathrm{I}) / \mathrm{PhOH}$ species similar to that of the oxygen complexes of hemoproteins with an $\mathrm{Fe}-\mathrm{O}_{2}$ stretch at $570-575 \mathrm{~cm}^{-1}$ isotopically shifted by $26 \mathrm{~cm}^{-1}$ upon using ${ }^{18} \mathrm{O}_{2}{ }^{21,22}$ The dioxygen complex is diamagnetic as evidenced by ${ }^{1} \mathrm{H}-\mathrm{NMR}$ and ${ }^{19} \mathrm{~F}-\mathrm{NMR}$. Note that the chemical shift of the $\mathrm{CF}_{3}$ marker is shifted by $\sim 2.5 \mathrm{ppm}$ in the dioxygen complex compared to the parent deoxy species. Moreover, the $\mathrm{Fe}(\mathrm{III})-\mathrm{O}_{2} / \mathrm{Cu}(\mathrm{I})$ species is EPR silent. The dioxygen complex of a model which does not have a covalently attached phenol is stable at room temperature.

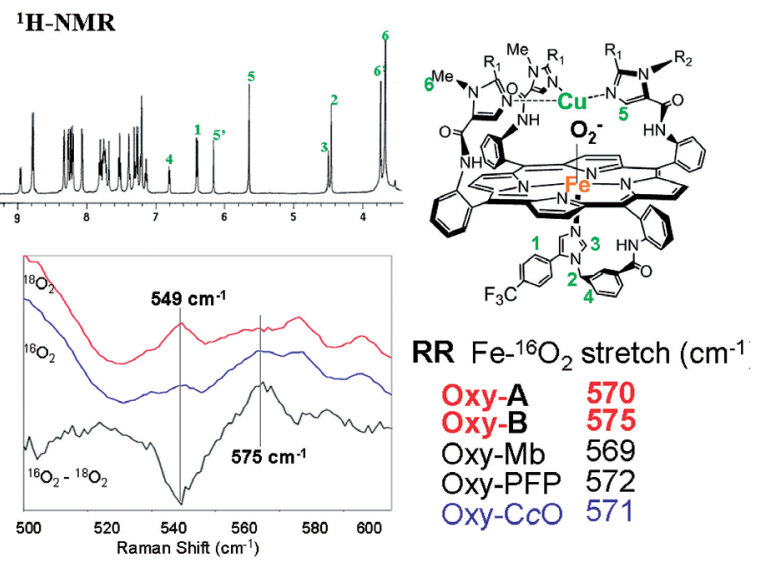

Fig. 6 The oxygen complex: characterization by ${ }^{1} \mathrm{H}-\mathrm{NMR}$, and resonance Raman. $\left(\mathrm{R}_{1}=\mathrm{H}, \mathrm{Pr} ; \mathrm{R}_{2}=\mathrm{Me}, \mathrm{O}-\mathrm{C}_{6} \mathrm{H}_{4} \mathrm{OH} ; \mathrm{A}\right.$ : model without phenol; $\mathrm{B}$, with phenol). ${ }^{21,22}$

The implication of phenol and $\mathrm{Cu}$ in the catalytic process was first confirmed in single turnover studies. The oxygen complex of a model that does not have a Tyr244 mimic reacts intermolecularly with an excess of exogenous hindered phenols leading to phenoxyl radicals, characterized by EPR, and an $\mathrm{Fe}(\mathrm{IV})-$ oxo, characterized by $\mathrm{O}$-atom transfer reactions with triphenylphosphine. ${ }^{23}$ The stoechiometry in phenoxyl radical formed indicates that the oxoferryl species also reacts with one equivalent of phenol. The single turnover reaction was also examined with a model that has the covalently bound Tyr244 mimic. However, because this model has a built-in phenol, its oxygen complex is not stable above $-40^{\circ} \mathrm{C}$. At this temperature it undergoes intramolecular reaction with the Tyr244 mimic: this faithfully reproduces the single turnover reaction that occurs in the enzyme leading to the formation of an oxoferryl-cupric-phenoxyl radical ("PM" intermediate) (Figure 7). ${ }^{21}$ Such a reaction is evidenced by a complex EPR signal that develops in intensity at $\mathrm{g}=2$, and resonance Raman with a peak at $770 \mathrm{~cm}^{-1}$ and $812 \mathrm{~cm}^{-1}$. 


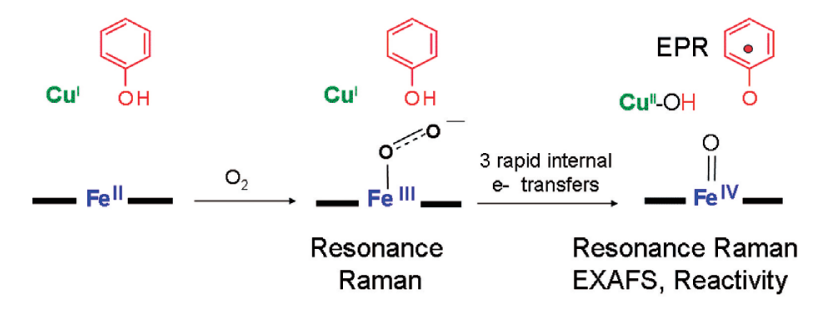

Fig. 7 Single turnover reaction between dioxygen and a functional CcO model having a built-in Tyr244 mimic.

\section{Self-assembled monolayers coated gold electrodes: functionalization, control of electron transfer, and electrocatalytic studies}

After the model was shown to form the same intermediates as the ones described in the enzyme, the next phase of the biomimetic studies consisted in connecting the model to a source of electrons to allow multiple turnovers. In the past the models were adsorbed on Edge-plane Graphite (EPG) Rotating Ring Disk electrode (RRDE). ${ }^{24}$ However, EPG has two major drawbacks: it is an ill-defined surface, and the electron transfer from EPG to the catalyst is several orders of magnitude faster than that of the electron delivery from Cyt. $\mathrm{c}$ to $\mathrm{CcO}$. Hence it is not biomimetic and a new method to control the rate of electron transfer from the electrode to the catalyst had to be developed. The EPG electrode was replaced by a self-assembled-monolayer (SAM)-coated gold electrode, and the catalyst was covalently attached to the SAM. Control of the rate of electron transfer to ferrocene by the nature of the SAMs had previously been reported. ${ }^{25-27}$ Such an assembly was prepared in four steps which are depicted in Fig. 8. The first phase consisted in the preparation of the gold-coated titanium inserts. It was performed in an evaporator where a layer of titanium $(\sim 50 \AA)$ was deposited on titanium inserts, followed by the deposition of a layer of gold $(\sim 500 \AA)$. The deposition of a titanium layer on top of titanium insert ensures better adhesion of gold. The ring disks were then immersed in a mixture of two different thiols, an alkyl thiol and an azideterminated alkylthiol. Because thiols react with gold leading to the formation of self-assembled monolayers, ${ }^{25}$ our mixture of thiols led to the formation of an azide-functionalized mixed $\mathrm{SAM}^{28}$ Such SAMs could be characterized by grazing-angle infrared reflectance spectroscopy (azide stretch at $\sim 2100$ $\mathrm{cm}^{-1}$ ), X-ray photoelectron spectroscopy, XPS (elemental composition on surface, looking specifically at the nitrogen 1s signals at $\sim 400 \mathrm{eV}$ and $405 \mathrm{eV}$ ), electrochemistry (capacitance, and "blocking experiment"), and ellipsometry (to determine the film thickness). In the presence of $\mathrm{Cu}(\mathrm{I})$ catalysts, these azide-modified surfaces react rapidly with acetylene-terminated species, such as ferrocene, ${ }^{28}$ or catalyst $\mathbf{1},{ }^{29}$ forming 1,2,3-triazoles, via "click" chemistry. This reaction initially reported in homogeneous solution by Sharpless is remarkable because it requires mild conditions, it is quantitative, and it is mainly performed in aqueous media. ${ }^{30}$ Moreover the triazole is robust and provides similar electronic coupling as previously reported linkers, such as esters. ${ }^{31}$ All these criteria were appealing for SAMs because they are very fragile. The use of click chemistry for the immobilization of molecules on solid surfaces, that we pioneered, ${ }^{32}$ is significantly superior to other coupling methods, which require harsh conditions and which often led to incomplete coupling. Unlike catalysts adsorbed on EPG, the resulting SAM functionalized with a catalyst was well-defined and could be characterized by: ${ }^{28,33-35}$ a) infrared spectroscopy (by monitoring the disappearance of the azide stretch), b) XPS spectroscopy (disappearance of $405 \mathrm{eV}$ peak and broadening of $400 \mathrm{eV}$ peak), c) ellipsometry (increase in film thickness of $\sim 2 \AA$ after coupling with ferrocene), d) cyclic voltammetry by examining the redox wave of the catalyst which was also used to estimate the surface coverage (that could be easily obtained from integrating the faradic current to get the overall charge). Immobilization of the redox species was confirmed after rinsing the SAM several times and observing a linear dependence of the peak current on the scan rate.

Site-isolation of the catalyst was governed by the alkyl azide thiol, and by the ratio between azide-terminated alkylthiol (linker) and simple alkyl thiol (diluent) in the thiol mixture before deposition. The control over rate of electron transfer to the redox active species through SAM was dependent upon the length and conjugation of the azideterminated alkylthiol linker, and to some extent to the nature

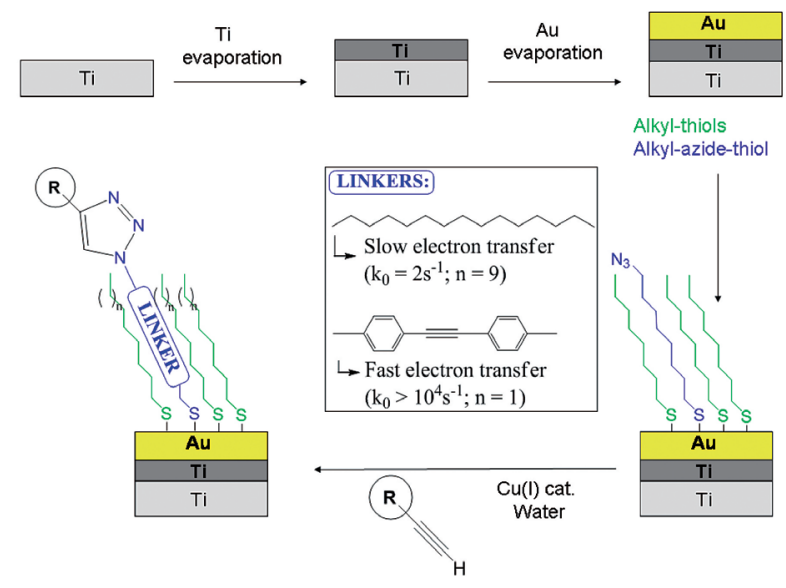

Fig. 8 Preparation and coating of gold electrodes with mixed selfassembled monolayers (SAM). Electron transfer rates from the electrode to the redox groups $\mathrm{R}$ can be tuned by the length and conjugaison of the linker. 
of the diluent. ${ }^{36}$ Electron transfer rates from electrode to ferrocene were measured using chronoamperometry and could be varied from $>10^{4}$ to $2 \mathrm{~s}^{-1}$ (Fig. 8), the slowest and biologically relevant rates were obtained on a C16 (linker)/ C16(diluent) SAM. ${ }^{36}$

The resulting RRDE built with a SAM-coated gold disk instead of an EPG disk was used as a normal RRDE. ${ }^{29}$ Dioxygen is reduced at the disk, and any partially reduced oxygen species, PROS, can be analyzed as $\mathrm{H}_{2} \mathrm{O}_{2}$ at the platinum ring which surrounds the disk (Fig. 9). ${ }^{24}$ The Pt ring is held at a sufficiently high potential to oxidize hydrogen peroxide and its current is displayed at the bottom of the voltammogram. The current measured at the disc is swept from positive to a negative potential where oxygen is reduced. The ring current is an indirect measure of the selectivity of a model in the catalytic reduction of oxygen.
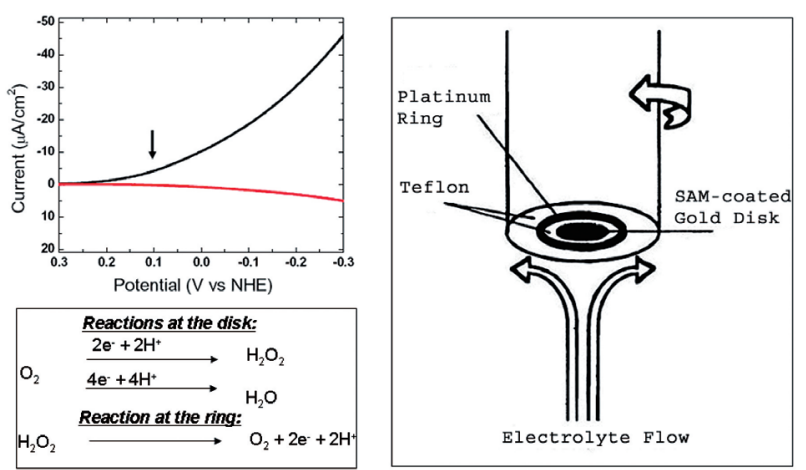

Fig. 9 The Rotating-Ring Disk Electrode (RRDE). Reactions occuring at the SAM-coated gold disk $\left(4 \mathrm{e}^{-}\right.$and $2 \mathrm{e}^{-} \mathrm{O}_{2}$ reduction, top black curve of the voltammogram) and at the Pt ring $\left(2 \mathrm{e}^{-} \mathrm{H}_{2} \mathrm{O}_{2}\right.$ oxidation, bottom red curve of the voltammogram). PROS were measured at the onset potential (shown as an arrow).

Three models were immobilized and studied on a slow SAM, where the electron transfer rate to the catalyst is biologically relevant (Fig. 10). ${ }^{29} \mathrm{~A}$ functional $\mathrm{CcO}$ model bearing all three redox active species found in the enzyme (heme, $\mathrm{Cu}_{\mathrm{B}}$, Tyr244, written $\mathrm{FeCuPhOH}$ ) catalyzes the selective $4 \mathrm{e}^{-}$reduction of dioxygen at physiological potential and $\mathrm{pH}$, under rate-limiting electron flux (as occurs in $\mathrm{CcO}$ ). Under slow and biologically relevant electron transfer rate $\left(2 \mathrm{~s}^{-}\right.$ ${ }^{1}$, to ferrocene), this model selectively reduces $\mathrm{O}_{2}$ with a small leakage of PROS. However, at such a slow regime of electron transfer, a second model labeled $\mathrm{FeCu}$ and that lacks one of the two distal redox centers, such as Tyr244 mimic, will release about twice as much PROS than the complete model. The third model, an Fe-only species, that does not possess any of the distal redox centers releases even more PROS and rapidly decays.

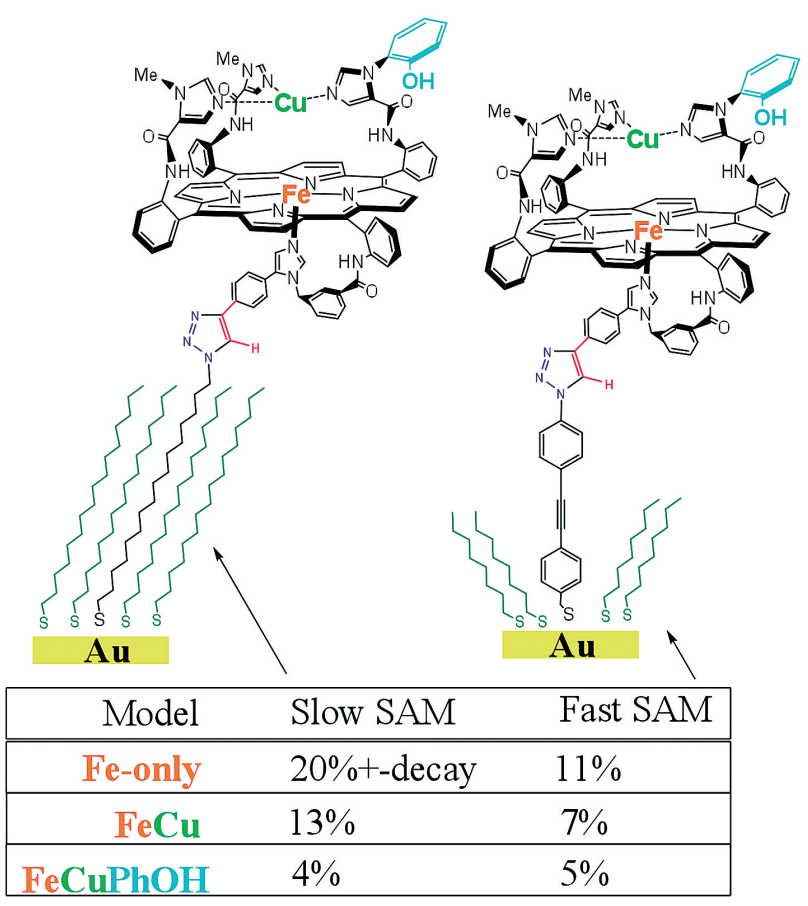

Fig. $10 \mathrm{CcO}$ models immobilized on SAM-coated gold electrodes. Percentage of electrons leaked as PROS as a function of slow vs fast SAM.

When these models were studied on fast SAMs the formation of PROS was less, even with the Fe-only species, and the difference in selectivity was less pronounced. These results suggest that under abiological conditions $\mathrm{Cu}_{\mathrm{B}}$ and Tyr244 mimic are not required to affect $4 \mathrm{e}$ - reduction of dioxygen, because a rapid flux of electrons arrives from the electrode. However, under biological conditions, the slow $\mathrm{SAM}, \mathrm{Cu}_{\mathrm{B}}$ and the phenol are needed to rapidly deliver electrons to the active site. Despite significant selectivity of the catalysts, about $6 \%$ of electrons are still lost as PROS. This is because of the hydrolysis of the oxygen complex which is promoted by electrophiles such as protons. ${ }^{37}$

\section{Conclusion}

We have shown that gold electrodes could be coated with mixed azide-functionnalized self assembled-monolayer, and an acetylene-terminated $\mathrm{Fe} / \mathrm{Cu} / \mathrm{PhOH} \mathrm{CcO}$ model 1 could be covalently attached to it by click chemistry. The nature of the SAM could tune the electron transfer rate to the model to a point where rates became biologically relevant. Under such conditions of rate-limiting electron flux, but also at physiological $\mathrm{pH}$ and potential, $\mathrm{CcO}$ model 1 that contains all the features of the $\mathrm{CcO}$ active site catalytically reduces oxygen by four-electrons with a high degree of selectivity. 


\section{Acknowledgments}

1- NIH for funding, grant GM-17880-35 and GM-69658-R01.

2- R.A.D for a Lavoisier Fellowship.

\section{References}

1) S. FergusonMiller, and G. T. Babcock, Chem. Rev. 96, (7), 28892907 (1996)

2) G. T. Babcock, and M. Wikstrom, Nature 356, (6367), 301-309 (1992)

3) J. P. Abrahams, A. G. W. Leslie, R. Lutter, and J. E. Walker, Nature 370, 621 (1994).

4) E. Cadenas, and K. J. A. Davies, Free Rad. Biol. Med. 29, 222-230 (2000)

5) T. Tsukihara, H. Aoyama, E. Yamashita, T. Tomizaki, H. Yamaguchi, K. Shinzawa-Itoh, R. Nakashima, R. Yano, and S. Yoshikawa, Science 1996, (272), 1136-1144 (1996).

6) T. Tsukihara, H. Aoyama, E. Yamashita, T. Tomizaki, H. Yamaguchi, K. Shinzawa-Itoh, R. Nakashima, and R. Yaono, Science (Washington D C) 269, (5227), 1069-1074 (1995).

7) S. Iwata, C. Ostermeier, B. Ludwig, and H. Michel, Nature 376, 660-669 (1995)

8) E. Pinakoulaki, U. Pfitzner, B. Ludwig, and C. Varotsis, J. Biol. Chem. 277, 13563-13568 (2002).

9) D. A. Proshlyakov, M. A. Pressler, C. DeMaso, J. F. Leykam, D. L. Dewitt, and G. T. Babcock, Science 290, 1588-1591 (2000).

10) M. Iwaki, A. Puustinen, M. Wikstrom, and P. R. Rich, Biochemistry 45, 10873-10885 (2006)

11) D. A. Proshlyakov, M. A. Pressler, and G. T. Babcock, Proc. Natl. Acad. Sci. U. S. A. 95, 8020-8025 (1998)

12) E. A. Gorbikova, I. Belevich, M. Wikstrom, and M. I. Verkhovsky, Proc. Natl. Acad. Sci. U. S. A. 105, 10733-10737 (2008).

13) S. Yoshikawa, T. Tsukihara, and K. ShinzawaItoh, BiochemistryMoscow 61, (11), 1369-1376 (1996).

14) R. A. Decréau, J. P. Collman, Y. Yang, Y. Yan, and N. K. Devaraj, J. Org. Chem. 72, (8), 2794-2802 (2007).

15) J. P. Collman, R. A. Decréau, and C. Zhang, J. Org. Chem. 69, (10), 3546-3549 (2004)

16) J. P. Collman, M. Bröring, L. Fu, M. Rapta, R. Schwenninger, and A. Straumanis, J. Org. Chem. 63, (23), 8082-8083 (1998).

17) J. P. Collman, M. Bröring, L. Fu, M. Rapta, and R. Schwenninger, J. Org. Chem. 63, (23), 8084-8085 (1998).
18) J. P. Collman, Z. Wang, M. Zhong, and L. Zeng, J. Chem. Soc., Perkin Trans. 1, 1217 - 1222 (2000).

19) J. F. O'Connell, J. Paquette, W. E. Yelle, W. Wang, and H. Rapoport, Synthesis, 767-771 (1988).

20) J. P. Collman, C. J. Sunderland, and R. Boulatov, Inorg. Chem. 41, (8), 2282-2291 (2002).

21) J. P. Collman, R. A. Decréau, Y. Yan, J. Yoon, and E. I. Solomon, J. Am. Chem. Soc. 129, (18), 5794-5795 (2007).

22) J. P. Collman, C. J. Sunderland, K. E. Berg, M. A. Vance, and E. I. Solomon, J. Am. Chem. Soc. 125, 6648-6649 (2003).

23) J. P. Collman, R. A. Decréau, and C. J. Sunderland, Chem. Comm. (37), 3894-3896 (2006).

24) J. P. Collman, R. Boulatov, C. J. Sunderland, and L. Fu, Chem. Rev. 104, 561-588 (2004).

25) C. E. D. Chidsey, Science 251, 919-922 (1991).

26) S. Creager, C. Y. Yu, C. Bamdad, S. O'Connor, T. MacLean, E. Lam, Y. Chong, G. T. Olsen, J. Luo, M. Gozin, and J. F. Kayyem, J. Am. Chem. Soc. 121, 1059-1064 (1999)

27) H. O. Finklea, and D. D. Hanshew, J. Am. Chem. Soc. 114, 31733181 (1992).

28) J. P. Collman, N. K. Devaraj, and C. E. D. Chidsey, Langmuir 20, (4), 1051-1053 (2004)

29) J. P. Collman, N. K. Devaraj, R. A. Decréau, Y. Yang, Y.-L. Yan, W. Ebina, T. A. Eberspacher, and C. E. D. Chidsey, Science 315, (5818), 1565-1568 (2007).

30) H. C. Kolb, M. G. Finn, and K. B. Sharpless, Angew. Chem. Int Ed. 40, (11), 2004-2021 (2001).

31) N. K. Devaraj, P. H. Dinolfo, C. E. D. Chidsey, and J. P. Collman, J. Am. Chem. Soc. 128, (6), 1794-1795 (2006).

32) N. K. Devaraj, and J. P. Collman, QSAR \& Comb. Sci. 26, (11-12), 1253-1260 (2007)

33) J. P. Collman, N. K. Devaraj, T. P. A. Eberspacher, and C. E. D. Chidsey, Langmuir 22, (6), 2457-2464 (2006).

34) C. E. D. Chidsey, and D. N. Loiacono, Langmuir 6, (3), 682-691 (1990).

35) D. A. Offord, S. B. Sachs, M. S. Ennis, T. A. Eberspacher, J. H. Griffin, C. E. D. Chidsey, and J. P. Collman, J. Am. Chem. Soc. 120, 4478-4487 (1998).

36) N. K. Devaraj, R. A. Decréau, W. Ebina, J. P. Collman, and C. E. D. Chidsey, J. Phys. Chem. B 110, (32), 15955-15962 (2006).

37) M. Momenteau, and C. A. Reed, Chem. Rev. 94, (3), 659-698 (1994). 


\section{Profile}

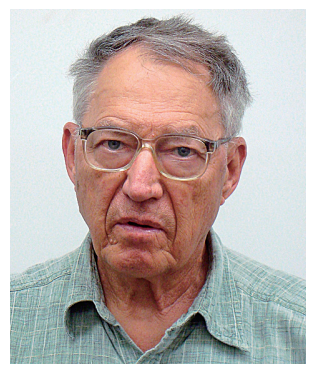

James P. Collman was born in 1932 in Beatrice city in the USA. He received his B. Sc degree (1954) and M. Sc (1956) from the University of Nebraska. He received a Ph. D. (1958) from the University of Illinois under the supervision of Professor R. C. Furson. From 1958 to 1967 he was appointed an associate professor of the University of North Carolina at Chapel Hill. In 1967 he was appointed Professor of Chemistry at Stanford University, His research interest lies in the general area of coordination chemistry, organometallic chemistry and inorganic chemistry. His main research interest lies in the development of functional and structural analogs of the active sites in heme proteins, such as cytochrome c oxidase. His work has been recognized by many awards, and he is a member of the National Academy of Sciences.

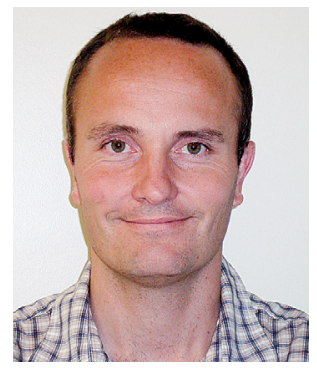

Richard A Decréau was born in 1970 in Saint-Germain-en-Laye city in France. He received his B. Sc degree (1992) and M. Sc degree (1993) from the Université de Provence (Aix-Marseille I, France). He received a Ph. D. (1998) from the Université Paul Cézanne (Aix-Marseille III, France) under the supervision of Professor M. Chanon. From 1999 to 2000 he worked as a postdoctoral research fellow with Professor Charles Marson at University College London and Dr Kelvin E. Smith at Queen Mary and Westfield College. With a Lavoisier Fellowship in 2001 he joined the group of Professor James P. Collman at Stanford where he first worked as a postdoctoral fellow, then as a research associate and lab manager. His research interests lie in the general area of coordination chemistry, organic chemistry and biomimetic chemistry. 